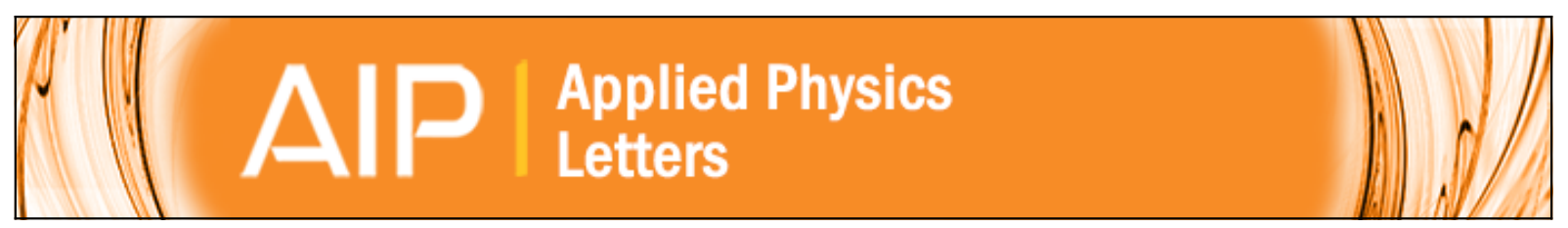

\title{
Optical and electrical characterization of InGaBiAs for use as a mid-infrared optoelectronic material
}

J. P. Petropoulos, Y. Zhong, and J. M. O. Zide

Citation: Applied Physics Letters 99, 031110 (2011); doi: 10.1063/1.3614476

View online: http://dx.doi.org/10.1063/1.3614476

View Table of Contents: http://scitation.aip.org/content/aip/journal/apl/99/3?ver=pdfcov

Published by the AIP Publishing

\section{Articles you may be interested in}

Strain- and kinetically induced suppression of phase separation in MBE-grown metastable and unstable GalnAsSb quaternary alloys for mid-infrared optoelectronics

J. Vac. Sci. Technol. B 31, 03C125 (2013); 10.1116/1.4799352

Temperature and Bi-concentration dependence of the bandgap and spin-orbit splitting in InGaBiAs/lnP semiconductors for mid-infrared applications

Appl. Phys. Lett. 101, 221108 (2012); 10.1063/1.4768532

Band gap tuning of InAs GaSb type-II superlattices for mid-infrared detection

J. Appl. Phys. 96, 2580 (2004); 10.1063/1.1776321

Epitaxial growth of InGaAsSb/AIGaAsSb heterostructures for mid-infrared lasers based on strain engineering J. Vac. Sci. Technol. B 22, 2240 (2004); 10.1116/1.1775196

Observation of spontaneous ordering in the optoelectronic material GalnNP

Appl. Phys. Lett. 84, 1299 (2004); 10.1063/1.1650045

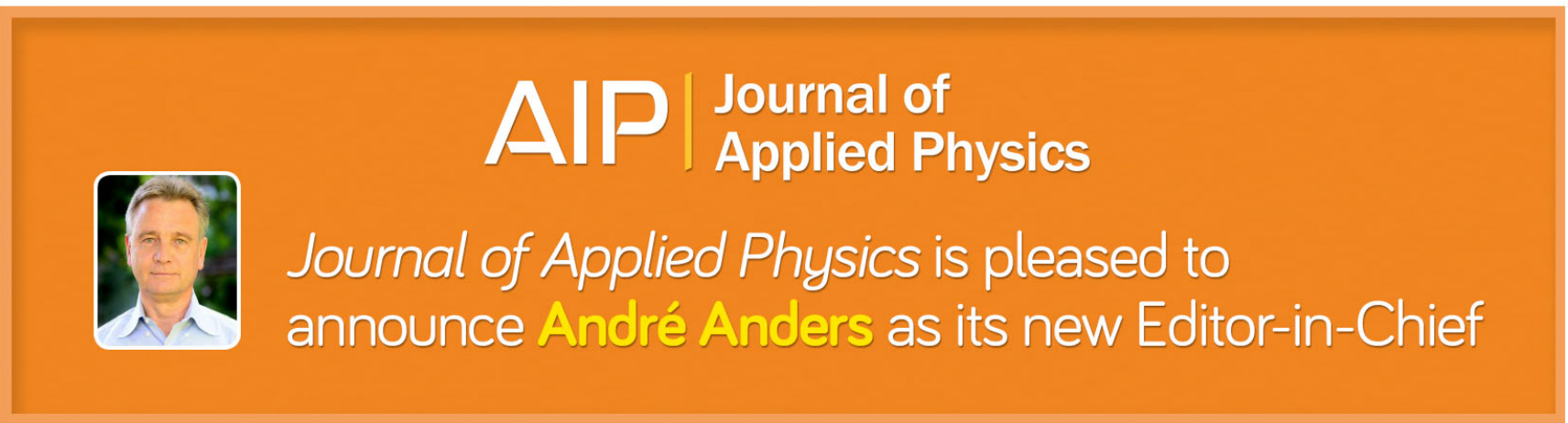




\title{
Optical and electrical characterization of InGaBiAs for use as a mid-infrared optoelectronic material
}

\author{
J. P. Petropoulos, ${ }^{1}$ Y. Zhong, ${ }^{2}$ and J. M. O. Zide ${ }^{2, a)}$ \\ ${ }^{1}$ Department of Electrical and Computer Engineering, University of Delaware, Newark, Delaware 19716, USA \\ ${ }^{2}$ Department of Materials Science and Engineering, University of Delaware, Newark, Delaware 19716, USA
}

(Received 7 June 2011; accepted 28 June 2011; published online 19 July 2011)

\begin{abstract}
$\mathrm{In}_{0.53} \mathrm{Ga}_{0.47} \mathrm{Bi}_{\mathrm{x}} \mathrm{As}_{1-\mathrm{x}}$ films were grown on InP:Fe substrates by molecular beam epitaxy, with Bi concentrations up to $\mathrm{x}=3.60 \%$. Bi content in the epilayers was determined by Rutherford backscattering spectroscopy, and channeling measurements show Bi incorporating substitutionally. Unlike previous work, electrical and optical data are obtained for all samples. A redshift in peak wavelength of about $56 \mathrm{meV} / \% \mathrm{Bi}$ was observed using spectrophotometry. The valence band anti-crossing model is applied, showing $\mathrm{In}_{\mathrm{y}} \mathrm{Ga}_{1-\mathrm{y}} \mathrm{Bi}_{\mathrm{x}} \mathrm{As}_{1-\mathrm{x}}$ lattice-matched to InP is possible by varying the composition, with a theoretical cutoff wavelength of about $6 \mu \mathrm{m}$. (C) 2011 American Institute of Physics. [doi:10.1063/1.3614476]
\end{abstract}

Bismuth containing III-V alloys have garnered much attention over the last few years due to their interesting properties. Bismuth is the largest and heaviest group $\mathrm{V}$ element with an energy level that resides in the valence band of most III-V materials. Due to this fact and the phenomenon of valence band anti-crossing (VBAC), introducing Bi into an alloy will cause a much larger bandgap reduction than predicted by the virtual crystal approximation (VCA). ${ }^{1}$ Valence band anticrossing occurs due to the degeneracy between the Bi electronic states and the valence band of the host matrix; this violates the Pauli exclusion principle, causing a split and upward shift of the valence band, leading to an anomalously large reduction in the bandgap. ${ }^{1,2}$ This phenomenon has been observed in the alloy $\mathrm{GaBi}_{\mathrm{x}} \mathrm{As}_{1-\mathrm{x}}$, grown by metalorganic vapor phase epitaxy ${ }^{3}$ and molecular beam epitaxy (MBE), ${ }^{4,5}$ with reported $\mathrm{Bi}$ concentrations upwards of $\mathrm{x}=10 \%$. $^{6,7}$ More recently, $\mathrm{Bi}$ has been incorporated into InGaAs by MBE, forming the quaternary alloy $\mathrm{In}_{\mathrm{y}} \mathrm{Ga}_{1-\mathrm{y}} \mathrm{Bi}_{\mathrm{x}} \mathrm{As}_{1-\mathrm{x}} \cdot{ }^{8} \mathrm{InGaAs}$ (lattice-matched to InP) is a well-developed material system with applications in optoelectronics for telecommunications and near infrared wavelengths. Due to VBAC, a small percentage of $\mathrm{Bi}$ can reduce the bandgap of InGaBiAs further, pushing peak wavelengths into the mid-infrared range. We report on the prospects for InGaBiAs lattice-matched to InP. The only III-V based materials available for this infrared region are InAs, InSb, and strained InGaAs. The lattice constants of InAs and InSb (6.058 $\AA$ and $6.479 \AA$, respectively) are far too large to be used in existing InGaAs/InP systems. Strained InGaAs can be used on InP up to about $2.5 \mu \mathrm{m}$, but the lattice strain hampers electrical performance. Latticematched InGaBiAs is likely to have better performance and more flexibility than strained InGaAs, InAs, and InSb.

Most of the current available literature focuses on the growth conditions and properties of $\mathrm{GaBi}_{\mathrm{x}} \mathrm{As}_{1-\mathrm{x}}$, with encouraging results. The reported change in $\mathrm{GaBi}_{\mathrm{x}} \mathrm{As}_{1-\mathrm{x}}$ bandgap energies range from $-62 \mathrm{meV} / \% \mathrm{Bi}$ (Ref. 7) to -84 meV/\%Bi. ${ }^{4}$ This is significant when compared to the bandgap variations of other III-V alloys, $-12 \mathrm{meV} / \% \mathrm{In}$ and

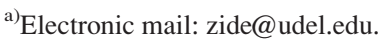

$-21 \mathrm{meV} / \% \mathrm{Sb}$ for InGaAs and GaAsSb, respectively. We found papers by Feng et al. ${ }^{8,9}$ are the only reports on the quaternary alloy $\mathrm{In}_{\mathrm{y}} \mathrm{Ga}_{1-\mathrm{y}} \mathrm{Bi}_{\mathrm{x}} \mathrm{As}_{1-\mathrm{x}}$, reporting $\mathrm{Bi}$ content up to $\mathrm{x}=2.5 \%$. They reported good crystalline quality with $\mathrm{Bi}$ incorporating substitutionally into the zinc-blende lattice, but bandgap values were not reported. We show that incorporating $\mathrm{Bi}$ into InGaAs has the same bandgap narrowing effect observed in GaBiAs. This allows us to push the wavelengths of these materials further into the infrared spectrum, with the possibility of lattice-matching to InP. This work focuses on the optical and electrical properties of $\mathrm{In}_{\mathrm{y}} \mathrm{Ga}_{1-\mathrm{y}} \mathrm{Bi}_{\mathrm{x}} \mathrm{As}_{1-\mathrm{x}}$, with emphasis on bandgap energy as a function of bismuth concentration. A model of the bandgap of $\operatorname{In}_{\mathrm{y}} \mathrm{Ga}_{1-\mathrm{y}} \mathrm{Bi}_{\mathrm{x}} \mathrm{As}_{1-\mathrm{x}}$ based on the VBAC is also presented, providing theoretical bandgap values of the quaternary alloy as a function of $y$ (In concentration) and $\mathrm{x}$ (Bi concentration).

Nine $\mathrm{In}_{0.53} \mathrm{Ga}_{0.47} \mathrm{Bi}_{\mathrm{x}} \mathrm{As}_{1-\mathrm{x}}$ samples were grown on (100)-oriented InP:Fe substrates via MBE using solid sources of In, $\mathrm{Ga}$ and $\mathrm{Bi}$, and a valved arsenic cracker. Prior to growth, native surface oxides were desorbed by heating the substrates to $565{ }^{\circ} \mathrm{C}$ with an arsenic overpressure and confirmed by changes in the reflection high energy electron diffraction (RHEED) pattern. Substrate temperature was calibrated and closely monitored using band-edge thermometry in transmission. After deoxidation, a $50 \mathrm{~nm}$ latticematched $\operatorname{In}_{0.53} \mathrm{Ga}_{0.47} \mathrm{As}$ buffer layer was grown to achieve a clean epitaxial surface. Growth temperatures ranged from 260 to $350^{\circ} \mathrm{C}$ and $\mathrm{As} / \mathrm{Bi}$ beam equivalent pressure (BEP) ratios were varied between 50 and 250 . Both the buffer and film layers were deposited at the same growth rate for each run, $0.6 \mu \mathrm{m} / \mathrm{h}$ to $0.8 \mu \mathrm{m} / \mathrm{h}$. RHEED patterns during growth showed streaky $4 \times 2$ reconstruction, indicating smooth surfaces and a coherent lattice. All sample surfaces were mirror-like and Bi droplets were not observed. Structural properties of the samples were ascertained by high resolution X-ray diffraction (HR-XRD) using a Philips X'Pert-MRD diffractometer and $\mathrm{Cu} K \alpha_{1}$ radiation. Most films exhibited wide peaks, indicating fully relaxed layers, which is to be expected in highly mismatched alloys. Film thicknesses were determined using HR-XRD fringe patterns (which indicate a 
smooth interface) and varied from 200 to $700 \mathrm{~nm}$. Rutherford backscattering spectroscopy (RBS) was used to calibrate XRD data and obtain Bi content for samples from each growth run, which ranged from $\mathrm{x}=1.10 \%$ to $3.60 \%$. RBS channeling measurements were also performed and confirm that $\mathrm{Bi}$ is incorporating substitutionally in the crystal lattice. It is worth mentioning that we attempted to use XRD film peak offsets to determine $\mathrm{Bi}$ concentrations; however, we found this impractical in a quaternary compound, as opposed to a ternary material, as small changes in other atomic species can also change the lattice constant. We found In incorporation was higher than expected and speculate that this may be due to $\mathrm{Bi}$ acting as a surfactant.

As expected, there were many similarities between the incorporation factors for InGaBiAs and those of GaBiAs., ${ }^{5,6}$ Bismuth concentration is dependent on three main parameters, substrate growth temperature, As/Bi ratio, and growth rate. Due to the way bismuth incorporates into the films, forming an adlayer on the sample surface, ${ }^{6}$ lower growth rates $(0.6 \mu \mathrm{m} /$ h), and smaller As/Bi BEP ratios $(\leq 100)$ led to increased Bi incorporation. However, the most critical factor for determining Bi concentration was substrate temperature; lower growth temperatures led to increased $\mathrm{Bi}$ content in our films. This makes temperature control and stability an extremely important factor; slight variations in substrate temperature can have large affects on the Bi concentration throughout the film, leading to non-uniform and lower quality films.

Optical data were acquired using a PerkinElmer Lambda 750 UV/VIS spectrophotometer. Transmission measurements were taken for each film and then used to calculate absorption coefficients using the Beer-Lambert law. Bandgap energies were then extrapolated from a linear fit of the $\alpha^{2}$ versus wavelength curves. ${ }^{11}$ Figure 1 is a plot of bandgap energy versus Bi concentration as well as a fit to the data, which will be discussed later. As observed in $\mathrm{GaBiAs},{ }^{4,7}$ the introduction of $\mathrm{Bi}$ into InGaAs causes a sharp decrease in the bandgap energy that follows a slightly parabolic trend. Using a linear fit, we estimate that the addition of $\mathrm{Bi}$ into the films causes a bandgap reduction of about $56.1 \mathrm{meV} / \% \mathrm{Bi}$. Although this number is lower than those observed in GaBiAs, ${ }^{4,7}$ starting at a lower bandgap value with $\operatorname{In}_{0.53} \mathrm{Ga}_{0.47}$ As will allow smaller bandgap energies to be achieved, even for moderate amounts of Bi. Bandgap values ranged from $0.669 \mathrm{eV}$ down to $0.496 \mathrm{eV}$. The lowest bandgap energy of $0.496 \mathrm{eV}$, for $\mathrm{x}=3.18 \%$,

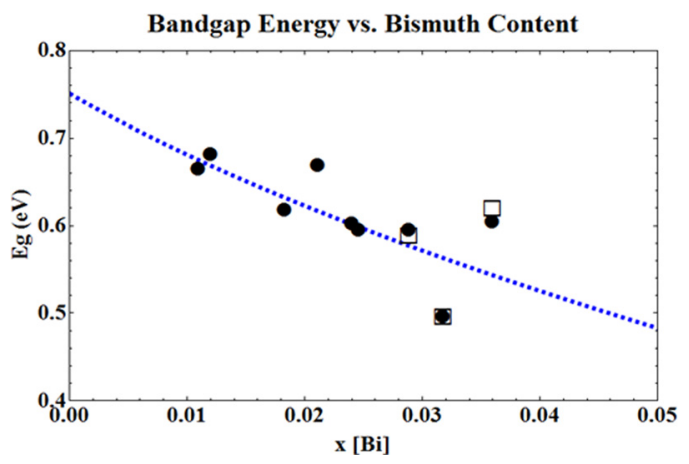

FIG. 1. (Color online) Filled circles: Bandgap energy for $\operatorname{In}_{0.53} \mathrm{Ga}_{0.47} \mathrm{Bi}_{\mathrm{x}} \mathrm{As}_{1-\mathrm{x}}$ as a function of Bi composition, $\mathrm{x}$. Dashed line represents values predicted by the VBAC model. Empty squares: FTIR results for last three data points. corresponds to a peak wavelength of about $2.5 \mu \mathrm{m}$, with a strain of about $0.75 \%$. For comparison, at $2.5 \mu \mathrm{m}$, strained InGaAs has an In composition of 0.8 , with a strain of $1.84 \%$. Bandgap data for last three samples were cross-checked using Fourier transform infrared spectroscopy (FTIR) and is in good agreement with spectrophotometry results.

Electrical properties of $\operatorname{In}_{0.53} \mathrm{Ga}_{0.47} \mathrm{Bi}_{\mathrm{x}} \mathrm{As}_{1-\mathrm{x}}$ were characterized using Hall-effect and four-point probe measurements in the van der Pauw geometry. All sample layers displayed n-type electrical conductivity, with electron concentrations ranging from 1 to $6 \times 10^{16} \mathrm{~cm}^{-3}$, and resistivities varying from 0.02 to $0.3 \Omega \mathrm{cm}$. Both electron concentration and resistivity generally increased with increasing Bi concentration. Mobilities of InGaBiAs have not been investigated in previous publications. Electron mobilities of our films were generally high and varied with Bi concentration, covering a range from 7400 to $350 \mathrm{~cm}^{2} / \mathrm{Vs}$, with increasing Bi concentration, as seen in Fig. 2. Electron mobilities in GaBiAs have been reported to be around $2000 \mathrm{~cm}^{2} / \mathrm{Vs}$ for a Bi content of about $1.5 \%{ }^{12}$ At $1.5 \% \mathrm{Bi}$, the electron mobility of our InGaBiAs films was higher, between 4400 and 7400 $\mathrm{cm}^{2} / \mathrm{Vs}$, which is to be expected when comparing an InGaAs based material with a GaAs based one. The relatively high mobilities exhibited by our films suggest that these materials can retain the superior electrical properties of InGaAs. As and In flux stability and $\mathrm{Bi}_{\text {III }}$ antisite defects ${ }^{13}$ may be the reason for the wide ranging mobility values and n-type conduction, as opposed to p-type observed in other GaBiAs publications. ${ }^{7,14}$ Scatter in the data may be explained by the varying growth conditions (especially growth rate and temperature) as well as the inherit variation in unintentionally doped samples.
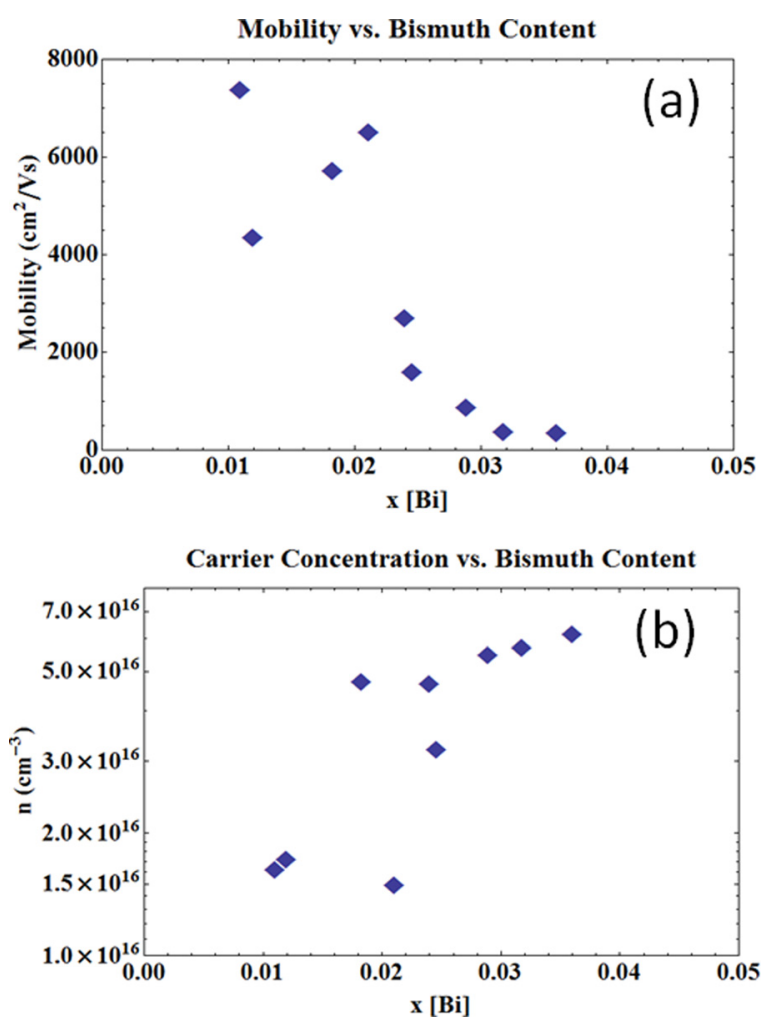

FIG. 2. (Color online) Mobilities (a) and electron carrier concentrations (b) for $\mathrm{In}_{0.53} \mathrm{Ga}_{0.47} \mathrm{Bi}_{\mathrm{x}} \mathrm{As}_{1-\mathrm{x}}$ as a function of $\mathrm{Bi}$ composition, $\mathrm{x}$. 

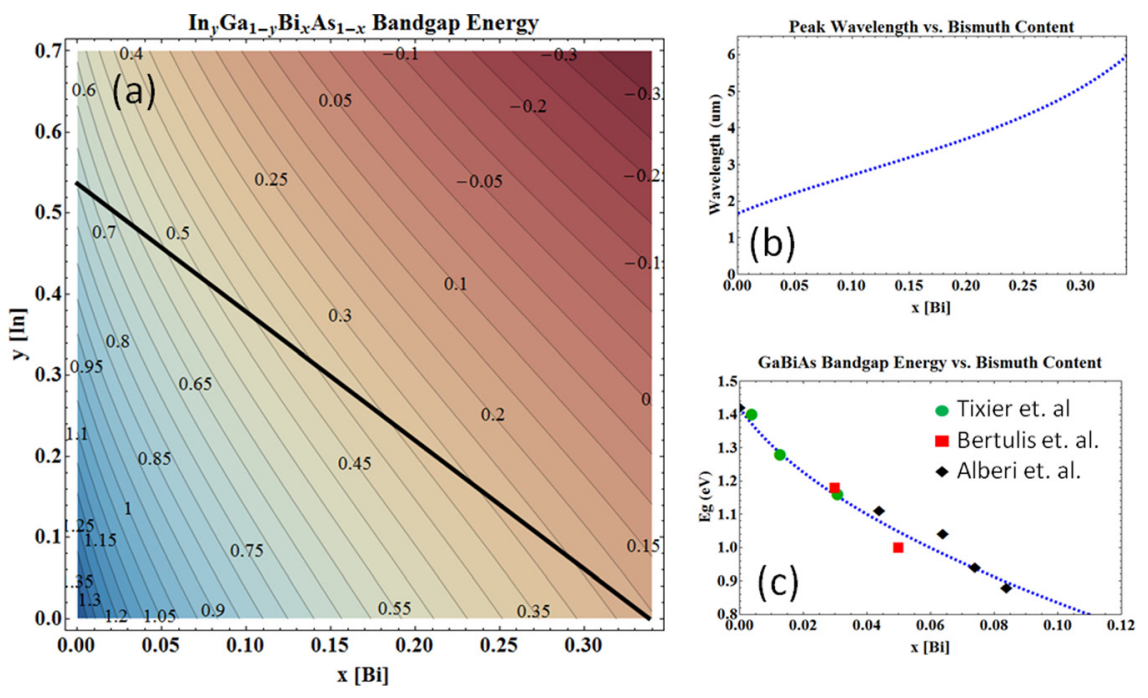

FIG. 3. (Color online) (a) Contour plot of bandgap values for $\mathrm{In}_{\mathrm{y}} \mathrm{Ga}_{1-\mathrm{y}} \mathrm{Bi}_{\mathrm{x}} \mathrm{As}_{1-\mathrm{x}}$, as a function of $\mathrm{Bi}$ (x) and In (y) compositions. The black line corresponds to compositions that are lattice-matched to InP. (b) Predicted peak wavelength for the latticematched composition versus Bi content. The theoretical cutoff wavelength is $6 \mu \mathrm{m}$, occurring at $34 \%$ Bi. (c) Experimental GaBiAs bandgap data compared to values predicted by the VBAC model (dashed line).
Unlike dilute nitrides, where the bulk of the bandgap change occurs in the conduction band, ${ }^{15-17}$ most of the change occurs in the valence band of dilute bismuthide materials. Both conduction and valence band anti-crossing models have been developed for nitrides and bismuthides, respectively. ${ }^{1,15,18,19}$ We utilize the valence band anti-crossing model to create a bandgap "map" of $\operatorname{In}_{y} \mathrm{Ga}_{1-y} \mathrm{Bi}_{\mathrm{x}} \mathrm{As}_{1-\mathrm{x}}$ as a function of $\mathrm{In}(\mathrm{y})$ and $\mathrm{Bi}(\mathrm{x})$ content. The model is an aggregate of the lattice constants and bandgap energies of the four binary constituents, $5.653 \AA$ and $1.42 \mathrm{eV}$ for GaAs, $6.058 \AA$ and $0.36 \mathrm{eV}$ for InAs, $6.324 \AA$ and $-1.45 \mathrm{eV}$ for $\mathrm{GaBi}$, and $6.686 \AA$ and $-1.63 \mathrm{eV}$ for InBi, respectively. ${ }^{10} \mathrm{As}$ is evident in Fig. 3(a), the bandgap of the quaternary alloy is non-linear as a function of composition, as predicted, generally decreasing with increasing In and Bi content. The thick black line corresponds to material compositions that are lattice-matched to InP, up to a limit of about $34 \% \mathrm{Bi}(0 \% \mathrm{In})$. A plot of the peak wavelength of lattice-matched $\mathrm{In}_{\mathrm{y}} \mathrm{Ga}_{1-\mathrm{y}} \mathrm{Bi}_{\mathrm{x}} \mathrm{As}_{1-\mathrm{x}}$, as a function of Bi (Fig. 3(b)), is also shown and yields a theoretical cutoff wavelength of about 6 $\mu \mathrm{m}$ for this material system. The bandgap energies for the 9 $\mathrm{In}_{0.53} \mathrm{Ga}_{0.47} \mathrm{Bi}_{\mathrm{x}} \mathrm{As}_{1-\mathrm{x}}$ samples grown thus far can be seen in Fig. 1 (symbols), with the theoretical bandgap values predicted by the VBAC model for these compositions. We found that the interaction strength - a measure of the atomic interaction between the Bi energy level and the valence band of the host matrix - is a function of both the In and Bi compositions. This differs from GaBiAs, where the interaction strength is solely dependent on the Bi concentration. ${ }^{1}$ Figure $3(\mathrm{c})$ is a slice of the model corresponding to $0 \% \mathrm{In}$, or just GaBiAs, with experimental bandgap values of $\mathrm{GaBi}_{\mathrm{x}} \mathrm{As}_{1-\mathrm{x}}$ reported by others shown for comparison. ${ }^{4,14,20}$ As can be seen, the VBAC model, with our modification to the interaction strength, fits this reported data extremely well, validating its accuracy.

In summary, $9 \mathrm{In}_{0.53} \mathrm{Ga}_{0.47} \mathrm{Bi}_{\mathrm{x}} \mathrm{As}_{1-\mathrm{x}}$ samples have been grown on InP substrates by MBE, with Bi concentrations up to $\mathrm{x}=3.6 \%$. Optical measurements showed a decrease in bandgap energy of about $56 \mathrm{meV} / \% \mathrm{Bi}$. All samples exhibited relatively high mobilities and moderate carrier concentrations at room temperature. An application of the VBAC model led to the discovery that the interaction strength between the Bi energy level and the valence band of InGaAs was not only dependent on $\mathrm{Bi}$ content but the In content as well. The VBAC model also shows that $\operatorname{In}_{\mathrm{y}} \mathrm{Ga}_{1-\mathrm{y}} \mathrm{Bi}_{\mathrm{x}} \mathrm{As}_{1-\mathrm{x}}$ lattice-matched to InP is possible by varying the $\mathrm{x}$ and $\mathrm{y}$ compositions, with a theoretical cutoff wavelength of $6 \mu \mathrm{m}$. It is worth noting that if modest amounts of strain are acceptable, longer wavelengths are possible for non lattice-matched compositions. The optical and electrical data presented here, combined with the predictions of the VBAC model, suggest that $\mathrm{In}_{\mathrm{y}} \mathrm{Ga}_{1-\mathrm{y}} \mathrm{Bi}_{\mathrm{x}} \mathrm{As}_{1-\mathrm{x}}$ is a promising material system for mid-infrared optoelectronic devices.

The authors wish to acknowledge Dr. Aaron Ptak for many useful discussions. The authors also wish to thank Brian McCandless at the Institute for Energy Conversion for help with spectrophotometry as well as Matthew Coppinger and Professor James Kolodzey for confirming FTIR measurements. Finally, the authors wish to acknowledge Leszek Wielunski for RBS data and the Office of Naval Research for financial support through the Young Investigator Program and additional seedling funding.

\footnotetext{
${ }^{1}$ K. Alberi et al., Phys. Rev. B 75, 045203 (2007).

${ }^{2}$ W. Shan, Phys. Rev. Lett. 82, 1221 (1999).

${ }^{3}$ K. Oe, Jpn. J. Appl. Phys. 41, 2801 (2002).

${ }^{4}$ S. Tixier et al., Appl. Phys. Lett. 82, 2245 (2003).

${ }^{5}$ M. Yoshimoto et al., Jpn. J. Appl. Phys. 42, L1235 (2003).

${ }^{6}$ X. Lu et al., Appl. Phys. Lett. 92, 192110 (2008).

${ }^{7}$ V. Pacebutas et al., J. Mater. Sci.: Mater. Electron. 20, 363 (2008).

${ }^{8}$ G. Feng et al., Jpn. J. Appl. Phys. 44, 1161 (2005).

${ }^{9}$ G. Feng, K. Oe, and M. Yoshimoto, Phys. Status Solidi A 203, 2670 (2006).

${ }^{10}$ A. Janotti, S.-H. Wei, and S. Zhang, Phys. Rev. B 65, 14 (2002).

${ }^{11}$ J. Tauc, Mater. Res. Bull. 3, 37 (1968).

${ }^{12}$ R. N. Kini et al., J. Appl. Phys. 106, 043705 (2009).

${ }^{13}$ R. N. Kini et al., Phys. Rev. B 83, 075307 (2011).

${ }^{14}$ K. Bertulis et al., Appl. Phys. Lett. 88, 201112 (2006).

${ }^{15}$ W. Shan et al., Phys. Status Solidi B 223, 75 (2001).

${ }^{16}$ W. Shan et al., J. Appl. Phys. 86, 2349 (1999).

${ }^{17}$ U. Tisch, E. Finkman, and J. Salzman, Appl. Phys. Lett. 81, 463 (2002).

${ }^{18}$ A. Lindsay, Physica E (Amsterdam) 21, 901 (2004).

${ }^{19}$ S. Francoeur et al., Appl. Phys. Lett. 82, 3874 (2003).

${ }^{20}$ K. Alberi et al., Appl. Phys. Lett. 91, 051909 (2007).
} 